\title{
India finally agrees to trials
}

\section{New DelhI}

AFTER nearly four years of vacillation, the Indian government has agreed to launch a human trial of the anti-leprosy vaccine developed by the World Health Organisation (WHO). India will be the third country, following Malawi and Venezuela, to test the vaccine.

The WHO vaccine, a combination of live BCG and heat-killed Mycobacterium leprae derived from armadillo, has been cleared by the drug controller and, according to Dr A.S. Paintal, director general of the Indian Council of Medical Research (ICMR), the trial, to be funded by ICMR, will start in January 1990.

The decision, reached at an ICMR expert committee meeting early in July, brings to end a long controversy that began at the time WHO proposed an Indian trial of the vaccine in 1985 (see Nature 317, 665; 1985). Although ICMR was keen, the proposal was voted down by a section of leprologists who claimed that a cheap, effective and safe indigenous vaccine was available and that there was no need to test the WHO vaccine (see Nature 328, 660; 1987).

Since then, two more candidate vaccines have emerged from Indian laboratories, prolonging the debate between those who favoured the WHO vaccine and those who favoured home-developed vaccines.

The plan is to use the BCG-M. leprae vaccine in phase-two trials on a few thousand healthy people to determine if there are any adverse effects. The trial will last four months. After that, the vaccine will be evaluated, along with two (or possibly three) Indian vaccines, in a single 'comparative' trial involving several thousand subjects at one location in south ENVIRONMENT

\section{Greener Framework}

\section{Paris}

AT A meeting on 27 July, the European Commission agreed a final version of its proposals for the next Framework Programme for $1990-94$. With a planned budget of 7,700 million ECU (to which will be added any carry-over from the present programme), the Commission has given a green tinge to its six principal lines of action. Apart from participation in the global change programme, the Commission proposes to support remote-sensing technology and the development of an 'environment-friendly' motor car. The proposals now have to be approved by the Council of Ministers in late September and by the European Parliament. The final programme should be adopted by the end of the year.
India. The vaccine that gives the best results, whether Indian or foreign, will be recommended for India's leprosy control programme.

Paintal says the trial will be designed and conducted by a committee of experts chosen by ICMR. WHO will simply supply the vaccine and provide one scientist to sit on the monitoring committee. This arrangement constitutes a major change from earlier vaccine trials where WHO assumed total control while Indian participation was limited to provision of infrastructural facilities and manpower. By declaring it an Indian and not a WHO trial, ICMR hopes to save WHO from any possible future allegations that it manipulated the results.

The two Indian competitors in the race are the ICRC vaccine developed at the Cancer Research Institute (CRI) in Bombay and the vaccine developed at the National Institute of Immunology (NII) in New Delhi from a soil mycobacterium. A third Indian vaccine developed at the
Central Drug Research Institute in Lucknow (from Mycobacterium habana) may also be included in the study.

The combined trial of all the vaccines is expected to put a stop to unhealthy competition among Indian groups (see Nature 333,$590 ; 1988$ ). "The question of which is the best vaccine for India can be found only by a comparative study", says NII director Dr G.P. Talwar. But CRI director Dr M.G. Deo still does not agree with ICMR's decision to bring in the WHO vaccine. "I have accepted participation in a true democratic fashion," he says.

Deo, who has been almost alone in campaigning against the armadillo vaccine trial, says it has none of the advantages of the ICRC vaccine developed in Bombay. He says ICMR should have restricted the comparative trials to Indian vaccines instead of bringing in the WHO vaccine which he criticizes on at least four counts: it has to be imported, requires multiple injections, is unsafe for children below 12 and is too expensive (Rs320 per dose against Rs1 for ICRC vaccine) for India, whose per capita expenditure on health is Rs43.

K. S. Jayaraman

\section{WOMEN IN SCIENCE}

\section{Still a soft female touch for doctorates}

\section{Washington}

THE number of US science doctorates awarded to woman has increased rapidly over the past decade, from 2,762 in 1978 ( 23 per cent of the total) to 3,936 in 1988 ( 36 per cent of the total), according to an annual survey commissioned by the Science and Engineering Education Sector Studies Group at the National Science Foundation.

But the overall rise is not distributed evenly among the sciences, as can be seen in the pair of graphs above. Women are doing better in the traditionally feminine 'softer' areas of science and worse in the pure sciences. Progress towards equality of the sexes has been slowest in mathematics; if things continue as they are, women will have to struggle for another 2,281 years before they receive as many doctorates in mathematics each year as men do now.

It is a different picture in the humancentred sciences. Women already receive the majority of psychology doctorates, a position they won in 1986 . They were victorious in anthropology (included within the social sciences) even earlier, becoming the majority in 1984. Last year, they took the lead in sociology (also included within the social sciences).

Overall, there has been steady change in both the life sciences, where women now take 33 per cent of the total number of doctorates compared to 27 per cent a decade ago, and in the physical sciences with a change from 11 per cent to 17 per cent.

But these overall gains conceal a few relentlessly masculine strongholds, such as physics, where only 130 out of 1,302 doctorates went to women in 1988.

The situation is even worse in engineering (not shown in the graphs). In 1988, just
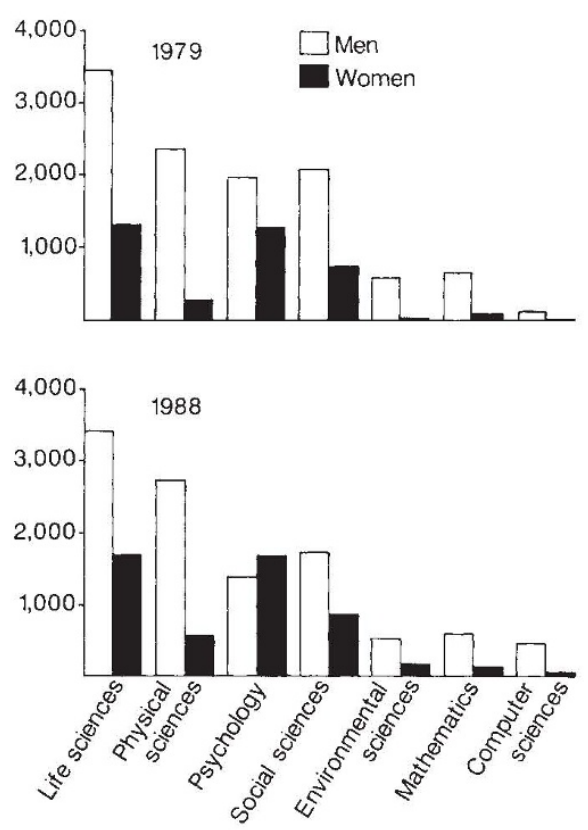

under seven per cent of engineering doctorates went to women.

Women have yet to reach positions higher up the hierarchy in significant numbers. Only 3 per cent of the members of the National Academy of Sciences are women.

Alun Anderson 